\title{
Effectiveness of an Integrative Competency-Based Approach on Masters Students in "Applied Informatics in Metallurgy" Programs
}

\author{
V.V. Osipov, Ph.D. in Physics \\ and Mathematics, Assoc. \\ Prof., T.P. Bugayeva, .PhD. in \\ Pedagogy, Assoc. Prof.., V.A. \\ Osipova, $\mathrm{PhD}$. in \\ Engineering, Assoc. Prof.., *
}

\author{
M.A. Loshchilova, $\mathrm{PhD}$. in \\ Pedagogy, Assoc. Prof., \\ Siberian Federal University \\ * National Research Tomsk \\ Polytechnic University \\ Yurga Institute of \\ Technology
}

\author{
660025, Krasnoyarsk, pr. \\ im. gazety Krasnoyarskiy \\ rabochiy, 95, tel. \\ 89504171809, e-mail: \\ osisi@yandx.ru
}

\begin{abstract}
Quality of any Master's program, which is as a component of two-level training, depends on Bachelor's and Master's programs cohesion in terms of content and methodology. At the same time, Master's programs target both Bachelors' skills further development, and graduates' proficiency further expansion through mastering integrative abilities, which in its turn contribute to job-related competency evolution as a whole. Integrative abilities include essential sets of interrelated competencies a specialist should have to perform in the workplace in an effective manner. The article raises an issue of integrative IT competencies, which should be developed with those Masters Students who pursue the "Applied Informatics in Metallurgy" program. Instructional measures to support teaching Masters Students in metallurgy include modified program content and sets of job related cases to help instructors enhance integrative content of learning by means of implementing active teaching methods, which allow forming integrated work methods and value attitude to profession among metallurgy Masters Students. A significant role of employers starts at an objective-setting stage, when they help educators determine competencies to be developed while teaching the program, and when they suggest burning questions to be investigated by Masters Students while doing their graduate research works. Such collaboration will definitely contribute to metallurgy industry development to the full.
\end{abstract}

Keywords- integrative competency-based approach, IT competency, job-related study, Musters Students.

\section{INTRODUCTION}

There are some basic trends which determine evolution in modern society. Globalization and growing diversity of the world are among those trends which result in regular and fast scientific knowledge updating, especially in the fields of engineering and applied sciences, and bring us to the era of information society. The main objective of Russian educators is to arrange learning environment in the way it will enhance each individual growth. An individual growth might be understood in the context of all personality attributes development, which factors in the ability of a person to adjust to the changing world demands fast, and to perform well. The task is being carried out with a significant influence of the above-mentioned trends on education system development, where education is considered as a part of a global strategy of the Russian nation social development. It is important to note the systematic impact these factors produce on national economy, culture, politics and education. Globalization promotes interpenetration of information and interdependence, which appears in all aspects of each country's affairs including economy, culture or politics; and results in information and communication densification or even universality of the globe. Globalization confronts education with universality and unification of educational programs and outcomes in order to create an adaptable educational environment.

New conditions of life and work make new demands for people (to work effectively with huge amounts of information, to make decisions in nonstandard situations and bear responsibility for them, to interact effectively in a team, to work creatively in the conditions of continuous education, etc.) and lead us to the next stage of social development. Personal qualities listed above do not stem from any subject knowledge and are not developed by the conventional education system.

Modernization of the Russian educational system in accordance with the Bologna process and the European integration principles has determined the need for a competency-based approach in which effectiveness of education is evaluated through the level of competence/competency development as an assessment of successful professional activity. An activity approach, jobrelated programs, as well as economic and social concerns have become priorities of education.

An analysis of research works which deal with theoretical studies and practical use of the competency-based approach in education shows that in spite of the fact that there is still a number of unsolved problems (definition of competence/competency basics, structure and content of competence/competency components, finding and approval of pedagogical conditions for competence/competency 
development and instructional support of teaching and learning, competence/competency level assessment) some aspects have been thoroughly elaborated.

In particular, a number of researchers use an integrative methodology which enhances practical and professional relation of education and provides new educational outcomes in the form of mastered integrated competencies (clusters of competencies) based on the synthesis of academic subjects (modules) and generalized methods of work. Examples of such integration are given in dissertational studies by L.S. Petrova (2013); V.V. Akhpashevai (2013); S.I. Tormasin (2013); V.V.Kalitina (2015); E.A. Kagakina (2015), etc. An analysis of these examples of competence/competency integration shows that they mostly establish interdisciplinary integration of related competencies (informationmathematical, mathematical sub competency, informationcommunication competency, program-algorithmic competency, integration of general cultural competencies). Within this research, the problem of IT competency development is posed. In this regard, it is necessary to combine academic learning with job-related environment, so to receive synergetic effect in training employees. The synergetic effect occurs when we integrate intellectual and engineering resources of universities and industrial enterprises.

The problem of integrating competencies and making up clusters becomes urgent when we assess education outcomes, which include from twenty to thirty competencies listed in the Russian Federation State Standard of Higher Education. In these conditions, it is important to form clusters of competencies for each professional activity. The research work is aimed at investigating graduate students' IT competency, which is integrative in its nature and is developed in the process of doing graduate research works.

\section{LITERATURE REVIEW}

To identify conditions and mechanisms, which serve to develop IT competency, it is necessary to specify the meaning and the essence of the IT competency concept, which is complex and consists of different interconnected parts.

Analysis of research studies carried out by different investigators shows that many aspects of the integration problem have been studied well. Integration through intersubject links is described by G.I. Baturina, V.N. Maksimova, et al. Interdisciplinary integration of different subjects taught within a curriculum was investigated by S.I. Hesse, A.I. Tymoshenko, and others. N.S. Antonova, M.N Berulava, N.K. Chapaev provide theoretical and practical confirmation of curriculum subjects integration effectiveness. Despite the fact that the problem of curriculum subjects integration has been studied widely, the content of interrelated subjects is one of major concerns among educators. Integration of competencies, viewed as an activity feature of a personality, has different nature and involves an integration of work methods and personal qualities with knowledge and skills related to integrated competencies.
To give a proper definition to IT competency, it is necessary to start with fact that computerization in education has generated a number of concepts that impose requirements for a person living and working in information environment. These requirements include mature IT competency which has different definitions which show its various aspects. The importance of informational culture as an ability to use technological tools to solve problems in non-standard situations is noted by A.A. Semenov [1]. O.G. Smolyaninova, to define information competency (IC), emphasizes inherent universal methods of data processing [2]. Functionality of IT competency is described in by S.V. Trishina and A.M. Witt [3]. M.P. Lapchik, A.A. Kuznetsov and E.K. Henner define personal ability to work in an IT led community through a set of competencies in informational and analytical, cognitive, communicative, social, technological and technical fields. They name the set as information and telecommunication competency (ITC), and highlight a high level of ITC functional capability [4-6]. A.V. Fedorova introduces a concept of media competency as an ability to carry out critical analysis, evaluation, creation and transmission of various media texts [7]. H.Lau relates a sequence of data processing operations (search, analysis, evaluation, identification and application) with IT literacy of a person [8]. Some researchers use the term digital literacy to address the issue. Z.G. Burchinall describe the ability to find and use information as IT literacy [9].

Z. Zimberg, S / Olof and T. Sanna extend the content of this concept by a value component [10]. In E.W. Horton's works, the structure of IT literacy is described as knowledge and ability to operate hardware, software and network IT tools as well as knowledge, and abilities to use means of communication in information environment [11].

In the studies by M. Knobel, Y. Eshet-Alkalai, IMP / Tornero, the content of digital literacy is much more complicated in comparison with IT literacy. It includes personal qualities which make a person a successful performer in digital environment, who acts in accordance with ethics rules and associates his/her own development as a part of a digital community prosperity [12-14]. We share the opinion of A.D. Arnautova, E.M. Zaitseva that properly formed IT competency with Masters students taught within a particular program depends on information tasks and software products relevant to their future profession $[15 ; 16]$.

Analysis of various interpretations of such relational terms as information competency, informational culture, IT literacy, digital literacy, or IT competency made it possible to distinguish some features of the phenomenon, i.e. its features, integrative character, dynamic nature and application scope. Taking into account the researcher's opinion, we agree with A.D. Arnautov's interpretation of IT competency as an integrative, dynamic personal quality of a specialist which includes ability to consciously integrate IT into his/her work and solve IT problems to meet modern standards of engineering activity in the era of computerization [16]. When we consider metallurgy with its specific technological processes, the definition of IT competency should be enlarged with the necessity to obtain an integrative personal quality of a 
metallurgist, which expresses itself in willingness and ability to use IT to solve technological problems in metallurgical production.

\section{METHODS OF RESEARCH}

The research is conducted within the framework of a polyparadigmatic approach which combines classical and neoclassical methodology.

Systemic, personal-activity and competency-based approaches to the structure and to the process of teaching graduate students allow us to consider a learner as an activity person and give the priority to procedural training technologies.

An acmeological approach helps us to consider reflective and developing nature of a person. Contemporary education stipulates the need for a synergetic approach that increases effectiveness of education through implementation of ideas of openness and network arrangement, which makes education job-related. Authors also apply theoretical methods such as comparative analysis of homeland and other countries research materials on the subject of the research work, as well as regulatory documents analysis.

\section{RESULTS AND DISCUSSION}

Complex, systematic and interdisciplinary nature of professional activity in metallurgical industry requires an integrative approach as a dominant strategy in training modern-day professionals.

Evolution of information society projected onto the sphere of production changed the metallurgists' work nature.

To ensure successful performance in the conditions of manufacturing computerization, specially trained personnel, capable of solving current problems in the aspects of metallurgical industry computerization and automation, are required [17]. Training is carried out within the Applied Informatics in Metallurgy Masters program.

Upon completing the program, graduates are able to:

- apply IT systems design methods and technology to solve urgent problems of metallurgical production;

- use special state-of-the-art software to analyze and improve technological processes which already exist;

- control technological processes by means of IT equipment;

- formulate tasks to develop a systems control process;

- use system analysis of information processes, set and solve applied tasks, model information processes;

- develop requirements for those who create or further develops IT equipment and supplies.

A set of these competencies forms a special cluster. Realization of the cluster objectives ensures that integral qualities of a Master in metallurgy will be developed.

When compiling the curriculum of the educational program, a balance is observed between fundamental (mathematical methods in solving applied metallurgy tasks, methodology and technologies for information systems design, modern-day software for modeling technological processes, mathematical logic) and applied (modeling of technological processes in metallurgy, project management, modeling dynamic processes, a laboratory-computational workshop on solving applied tasks) technological parts of the curriculum. It also provides continuous use of information technologies both as a means of training and as a means of solving problems of metallurgical industry.

Expansion of metallurgists' training for improving the quality of metallurgical production is carried out on the basis of using the potential of tools and applied information technologies to solve specific information tasks of metallurgical production. These tasks are:

1. Research and develop effective methods to implement information processes, and build information systems in application areas based on up-to-date ICT.

2. Organize and implement system analysis and reengineering of application and information processes, setting and solving applied problems.

3. Model application and information processes, and work out requirements to develop information systems and their components.

4. Organize and implement project feasibility studies, which develop automation and computerization projects for applied processes, creating information systems in application areas.

5. Manage computerization projects at enterprises and organizations, as well as decision-making on these projects, organizing and managing introduction of information systems application areas.

6. Manage the quality automated equipment handles application problems with; create information systems.

7. Organize and manage information systems performance.

8. Train and consult on automation and computerization of application problems; introduce information systems into application areas.

9. Develop mathematical methods and software to be used during applied econometric research work.

The task within the Master's degree program in Applied Informatics in Metallurgy was not just to raise the informational competency of Bachelors academic level but also to provide interrelation and interaction of engineering and informational components of training, which result in integrative IT competency development. This competency can be rated as a basic one within the Master's program we consider. It has a pronounced practical and professional character, can characterize quality of education and be an integrative indicator of a metallurgist's effectiveness in practical solution of information problems. The task can be solved within the framework of context learning technology (AA Verbitsky, 1987) involving professional practices identified in cooperation with employers.

In order to determine the conditions in which IT competency develops, its essence was revealed through its structure. Presuming that IT competency is activity-based, and having analyzed research works concerning quantitative and content structure of competency, authors have determined the IT competency structure. It includes motivational, cognitive- 
activity and reflexive-evaluative components. The motivational component shows the importance and value of using information and communication technologies to solve specific information problems in metallurgy industry. The cognitive-activity component includes theoretical knowledge and an ability to apply modern methods and tools of applied informatics for automation and computerization to solve different applied problems in metallurgy, including architecture and services of information systems design, modern information and communication technologies adaptation to applied production problems, effective design decisions making. In addition, the cognitive-activity component shows the mastery and practical use of special software products, including AnSys, ProCAST, SolidWorks.

The reflexive-evaluative component in the structure of IT competency ensures its dynamic character due to analysis and self-assessment of results obtained when solving information problems in metallurgy with the aim to identify rational methods for decision-making and to determine the level of IT competency as well as ways to improve it. Revealing the essence of IT competency, pedagogical conditions that contribute to its development within the learning process, were developed. Together with the employers authors have determined how information technologies might be used to model, study and manage metallurgical process:

- model technological processes;

- control parameters that cannot be measured directly;

- make forecasting models of changes in the main parameters of technological process (TP);

- calculate control actions;

- diagnose technological equipment and TP condition;

- study normal and emergency equipment operation modes;

- train personnel skills of optimal TP management;

- examine personnel knowledge and certifying qualification;

- improve developed algorithms and equipment operation;

- optimize a TP operation mode.

In this regard, integration is presented as a process and a result of competencies integration which provide a certain type of activity due to the features of the competencies involved, and nature of their integration in metallurgy. In a number of studies, related to the competencies integration issues, integration of various educational branches with informatics is being discussed and suggested.

In this work authors suggest that learning should be moved into the sphere of job-related activity through the participation of employers in the process of setting urgent problems to be investigated by Masters Students in their graduate research works, when educators design curriculum; and also through Masters Students' industrial work placement at partner enterprises. This allows integration of intellectual and material resources of an enterprise and university, which help achieve a synergistic effect in Masters Students teaching improvements.
The discussion aspect of this work is as follows: an integrative approach in education involves identification of an integration basis. Such a basis can combine separate competencies formed while studying at university. Disciplines of the curriculum which determine the dynamics of competency development should be integrated.

In [18] authors suggest a set of integrated disciplines which ensures that general cultural, and both general and special professional competencies will be developed. In these conditions, the contribution of each discipline into competency development defined by FSES in "Applied Informatics" (09.04.03) has been discussed.

In this research work, project activity which is ranked as the main one, was chosen as the integration basis for Master's program considered. The project activity allows authors to disclose uncertainty, offering different options for this.

Information technologies involved into project activity provide optimization of technological processes management. Development of predictive models, which help rationalize choice and change of key parameters, stimulate improvements in the context of metallurgy production computerization.

\section{CONCLUSION}

To develop IT competency of Masters Students in metallurgy means to teach them apply modern-day methods and tools of applied informatics to optimize metallurgical processes. This work of educators should be supported with the following pedagogical methods:

- modification of metallurgy disciplines content should be realized through the integration of information technology and specific software products into the curriculum;

- job-related cases of various complexity should make a sufficient part of an integrated education content;

- active teaching methods such as project activities, problem training, contextual training, production practice, etc should be used throughout the learning process.

Pedagogical integration mechanisms, presented in the paper, make it possible to develop IT competency of Masters Students in metallurgy by means of integrative education content, teaching and learning methods, and value attitude to the metallurgist profession.

The ideas suggested to further develop the integrative competency-based approach in teaching Masters Students in Applied Informatics in Metallurgy are based on integration of information technologies into the content of professional competencies of metallurgists in the conditions of information society, and might be used by educators to design curriculum for other Master's programs.

\section{REFERENCES}

[1] Semenov, A.L. Quality of informatization of education / A.L. Semenov // Education. - 2005. - No. 3. - P. 248-269.

[2] Smolyaninova, O.G. Development of methodical system of formation of informational and communicative competence of future teachers on the basis of multimedia technologies: Doctor thesis in Pedagogics: 13.00.02 / Smolyaninova Olga Georgievna. - St. Petersburg, 2002. - 504 p. 
[3] Witt, A.M. Development of informational competence of technical college students: PhD thesis in pedagogic: 13.00.08 / Witt Anastasia Mihailovna. - Chelyabinsk, 2005. - $200 \mathrm{p}$.

[4] Lapchik, M.P. ICT-competence of pedagogical personnel / M.P. Lapchik // monograph. - Omsk: Publishing House of the Omsk SPU, 2007.- 144 pp.

[5] Kuznetsov, A.A. Modern course of informatics: from elements to system / A.A. Kuznetsov, S.A. Beshenkov, E.A. Rakitina // Informatics and Education. - 2004. - No. 1. - P. 1-7.

[6] Henner, E.K. Formation of ICT competence of students and teachers in the system of continuous education / E.K. Henner // M.: BINOM. Laboratory of Knowledge, 2008. - 188 p.

[7] Fedorov, A.V. Media competence of personality: from terminology to indicators / A.V. Fedorov // Innovations in Education. - 2007. - No. 10. P. 75-108.

[8] Lau, H. A Guide to information literacy for lifelong learning / H. Lau;. M.: MOO WFP UNESCO "Information for All", 2007. - 45 p.

[9] Burchinall, L. G. The communications Revolution : America's Third Century Challenge [Electronic source] / L. G. Burchinall // The Future of Organizing Knowledge : Papers Presented at the Texas A \& M University Library's Centennial Academic Assembly, 24 сент. 1976. Texas. $-$ URL: http://personalpages.manchester.ac.uk/staff/drew.whitworth/burchinal t he_communications_revolution.pdf (reference date : 20.05.2017).

[10] Limberg, L. Three Theoretical Perspectives on Information Literacy [Electronic source] / L. Limberg, S. Olof, T. Sanna // Human IT : Journal for Information Technology Studies as a Human Science. 2012. - № 11. - C. 93-130. URL : http://etjanst.hb.se/bhs/ith/211/llosst.pdf (reference date : 20.08.2017).

[11] Horton, F.W. Understanding Information Literacy : A Primer [Electronic source] / UNESCO Information for All Programme. - 2008. $\begin{array}{ccccr}- & 95 & \text { c. } & \text { URL } & \text { : } \\ \text { http://unesdoc.unesco.org/images/0015/001570/157020e.pdf } & \text { (reference }\end{array}$ date : 20.08.2017).
[12] Knobel, M. Digital Literacies : Concepts, Policies and Practices / M. Knobel. - New York : Peter Lang Publishing, 2008. - 321 p.

[13] Eshet-Alkalai, Y. Experiments in Digital Literacy [Electronic source] / Y. Eshet-Alkalai, Y. Amichai-Hamburger // CyberPsychology \& Behavior. - № 7. - 2004. - P. 421-429.

[14] Tornero, J. M. P. Promoting Digital Literacy : Final Report / J. M. P. Tornero. - Understanding Digital Literacy. -2004. - URL: http://ec.europa.eu/education/archive/elearning/doc/studies/dig_lit_en.pd f.

[15] Loshchilova M. A., Lizunkov V. G., Zavyalova A. Professional Training of Bachelors in Mechanical Engineering, Based on Networking Resources// Procedia - Social and Behavioral Sciences. - 2015. - Vol. 206 : Linguistic and Cultural Studies: Traditions and Innovations, LKTI. - [P. 399-405]. — Title screen. - Reference: http://dx.doi.org/10.1016/j.sbspro.2015.10.073.

[16] 16. Zaitseva, E.M. Technology of managing informational competence development of students of radio engineering specialties: dis. ... cand. ped. Sciences: 13.00.08 / Zaitseva Elena Mikhailovna. - Izhevsk, 2007. $-194 \mathrm{p}$.

[17] Arnautov A.D. Formation of informational competence of future bachelors-metallurgists in the process of mastering the discipline "Information services" using a complex of information and technological problems: PhD thesis in Pedagogic: 13.00.02 / Arnautov Alexander Dmitrievich. - Krasnoyarsk, 2017. - 204 p.

[18] Loschilova M.A., Portnyagina E.V. Regional aspects of optimizing management of educational institutions / / In the world of scientific discoveries. - 2012. - No. 5. - P. 100-113.

[19] Osipov V.V. Integrated approach to formation of competencies in educational process. Osipov, T.P. Bugayeva // Modern high technologies. - 2007. - No. 1. - P. 140-144.

[20] Osipova S.I. Designing contents of master's program "Applied Informatics in Metallurgy" / S.I. Osipova, T.P. Bugaeva, V.V. Osipov, A.Yu. Semushev // Bulletin of KSPU them. V.P. Astafyieva. - 2017. No. 2 (40). - P. 98-102. 